
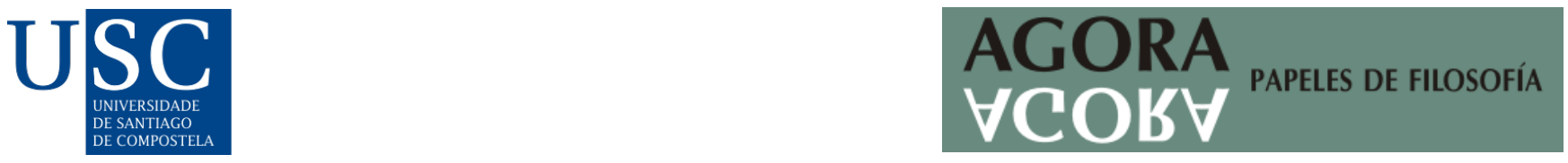

\title{
LA INTERPRETACIÓN ALEGÓRICA DE LOS POEMAS HOMÉRICOS EN EL PERIODO ARCAICO COMO EXÉGESIS FILOSÓFICA
}

\author{
Gastón Alejandro Prada ${ }^{1}$ D \\ ${ }^{1}$ Universidad de Buenos Aires, Argentina
}

Recibido: 10/02/2021; Aceptado: 30/06/2021

\section{Resumen}

Este trabajo estudia la interpretación alegórica de los poemas homéricos en el periodo arcaico a partir del corpus supérstite de los llamados «alegoristas»: Teágenes de Regio, Ferécides de Siros y Metrodoro de Lámpsaco. Se propone que, a través de esta perspectiva, los intérpretes hacen foco en algunos de los problemas metafísicos presentes en la Ilíada y la Odisea, trazando así filiaciones conceptuales con la filosofía presocrática. Se parte de la hipótesis de que la alegórisis de los poemas homéricos del periodo arcaico no constituye un mero discurso apologético como se da en épocas subsiguientes sino, en rigor, una decodificación de un lenguaje propio de la épica que permite plasmar determinadas nociones filosóficas en nuevas formas de enunciación del contexto arcaico y preclásico.

Palabras clave: alegórisis; poemas homéricos; filosofía; periodo arcaico.

\begin{abstract}
This work studies the allegorical interpretation of the Homeric poems in the archaic period from the surviving corpus of the so-called «allegorists»: Theagenes of Regius, Pherecides of Siros and Metrodoro of Lampsaco. It is proposed that, through this perspective, interpreters focus on some of the metaphysical problems present in the Iliad and the Odyssey, thus tracing conceptual affiliations with pre-socratic philosophy. It is based on the hypothesis that the alegórisis of the Homeric poems of the archaic period does not constitute a mere apologetic discourse as it occurs in subsequent times but, rather, a decoding of a language typical of the epic that allows to shape certain philosophical notions in new forms of enunciation of the archaic and pre-classical context.
\end{abstract}

Keywords: alegórisis; homeric poems; philosophy; archaic period.

\section{INTRODUCCIÓN}

Este trabajo estudia la interpretación alegórica de los poemas homéricos, entendida como un modo de abordaje filosófico, literario y filológico de la poesía en general ${ }^{1}$, originario del periodo arcaico y desarrollado durante las épocas subsiguientes. Se propondrá que, a través de esta 
perspectiva, los intérpretes hacen foco en algunos de los problemas metafísicos presentes en la Ilíada y la Odisea, trazando así filiaciones conceptuales con la filosofía presocrática. A lo largo de este artículo se trabajará con el corpus de los llamados «alegoristas» de la época arcaica que, de acuerdo con la evidencia supérstite, constituyen el punto de partida de este tipo de lectura sobre los poemas de Homero, ${ }^{2}$ sentando así las bases para el desarrollo de la alegórisis de los periodos subsiguientes: Teágenes de Regio, Ferécides de Siros y Metrodoro de Lámpsaco.

Se intentará mostrar que la alegórisis de los poemas homéricos del periodo arcaico no constituye un mero discurso apologético sino, en todo caso, una decodificación de un lenguaje propio de la épica que permite plasmar determinadas nociones filosóficas en nuevas formas de enunciación del contexto arcaico y preclásico. Esto hace posible clarificar la filiación y los vínculos directos que pueden trazarse entre los poemas homéricos -dando así un nacimiento prematuro a la historia de la filosofía- ${ }^{3}$ y el pensamiento presocrático.

Este trabajo no pretende abordar la vasta problemática que gira en torno a la hermenéutica que los alegoristas arcaicos han hecho de la épica homérica a través la totalidad del corpus supérstite. Más bien, las siguientes páginas se limitarán a presentar los diversos puntos de partida de los alegoristas arcaicos, exponiendo cuestiones en torno a la génesis y desarrollo del movimiento para, en segunda instancia, plantear algunos interrogantes, problemas y matices sobre el influjo que la interpretación alegórica ha tenido en algunos exponentes de la filosofía presocrática.

Se comenzará por un breve panorama de la alegórisis homérica y, a continuación, se presentará a los principales exponentes del periodo arcaico de quienes conservamos sus testimonios, exhibiendo el modo de análisis y abordaje textuales que realizan sobre determinados pasajes de los poemas homéricos. A su vez, con el objeto de mostrar determinada evolución de la alegórisis en la filosofía presocrática, se exhibirán brevemente algunos postulados de ciertos filósofos presocráticos que evidencian la posible herencia y filiación conceptual con dicho modo de interpretación. Por último, se plantearán algunos de los problemas a los que conlleva cierta concepción tradicional de la interpretación alegórica y, a partir de ello, se intentará precisar y reformular la noción de alegórisis homérica específicamente para el periodo arcaico.

\section{LA ALEGÓRISIS HOMÉRICA}

Con frecuencia se afirma que la alegórisis de los poemas homéricos surge como un modo de defensa frente a la crítica filosófica, sobre todo en torno a la representación de los dioses, llevada a cabo desde el siglo VI a.C. en adelante por varios filósofos, cuyo representante más famoso y paradigmático es Jenófanes de Colofón, con su objeción al antropomorfismo de los dioses. ${ }^{4}$ También Platón, tiempo más tarde, se presentará como recopilador y sintetizador de este enfoque crítico sobre la poesía tradicional en el marco de su proyecto filosófico-político. ${ }^{5}$ De este modo, la interpretación alegórica de los poemas homéricos surgiría como una reacción defensiva de parte de los admiradores de Homero frente a la crítica mordaz de los filósofos, con el fin de salvar las aparentes contradicciones presentes en los poemas en torno al comportamiento inaceptable de los dioses: su moralidad e inmoralidad humanas, las inverosímiles batallas entre divinidades con sus correspondientes lesiones, las metamorfosis de los dioses, etc. ${ }^{6}$ Este tipo de interpretación de los textos que se remonta al periodo arcaico es seguido por un trabajo muy prolífico en todos los periodos sin solución de continuidad. Diógenes de Apolonia en la época clásica (s. V a.C.), 
los gramáticos alejandrinos en la época helenística (ss. III-I a.C.), ${ }^{7}$ Heráclito (s. I d.C.) y PseudoPlutarco (s. II d.C.) en el periodo imperial y, a su vez, Eustacio de Tesalónica en Bizancio (s. XII d.C.), junto con su desarrollo a partir de los pensadores del Renacimiento hasta nuestros días: en todos estos periodos la alegórisis de los poemas homéricos ha tenido su lugar entre los filósofos y comentadores.

El término «ó́ $\lambda \lambda \eta \gamma \gamma o \rho i ́ \alpha »$ («decir otra cosa») pertenece al periodo posclásico y sus primeros usos se remontan a autores retóricos del periodo helenístico para designar un amplio rango de expresiones no literales que van desde las gnómai hasta los ainígmata. ${ }^{8}$ Plutarco (Moralia 19e) afirma que el concepto podría considerarse una sustitución del término griego «útóvoเ $\alpha{ }^{9}$ utilizado por Platón, como se exhibe más adelante- que nos remite a lo que la crítica usualmente ha denominado «interpretaciones alegóricas» (Ford 2002, p. 72). Ya desde época temprana hubo una considerable proliferación de autores alegóricos que se ubicaron entre los filósofos presocráticos y establecieron zonas de tensión dialógica con sus coetáneos. En el periodo helenístico, Aristarco distingue entre la alegoría - un recurso literario propio del poeta cercano a lo que se entiende por «metáfora» - y la alegórisis, perteneciente a los comentadores posteriores a Homero que le hacen decir al poeta cosas que en realidad nunca habría dicho (Schironi 2018, pp.140-141). ${ }^{10}$

\section{TEÁGENES DE REGIO}

Teágenes de Regio es el comentador de poesía más antiguo del que tenemos testimonio (8 2.13-14 DK). ${ }^{11}$ Probablemente por esta razón haya sido considerado por los críticos (antiguos y modernos) como un gramático o incluso un proto-filólogo. ${ }^{12} \mathrm{Su}$ obra se ha perdido, pero conservamos varias de sus ideas, la mayoría de ellas en los escolios a los poemas homéricos, en los que es citado directamente. Aunque tardío (s. III d.C.) -como la gran mayoría de las fuentes conservadas sobre estos autores presocráticos- ${ }^{13}{ }^{13}$ Porfirio (Quaest. Hom. Il. 20.67.1-23; Schrader 1880-1882) nos ofrece un testimonio de algunos comentarios de la lectura de los poemas homéricos de Teágenes. ${ }^{14}$ En su enfoque apologético de la épica homérica se sostiene que los episodios «inadecuados» en torno a los dioses deben interpretarse de un modo alegórico y no literalmente. Así, la lectura del filósofo habría consistido en interpretar los poemas homéricos atribuyéndole o añadiéndole un significado adicional o subyacente a lo expresado de modo literal. El ejemplo más conocido y, en general, el punto de partida sobre la cuestión es la Theomachía (Il.

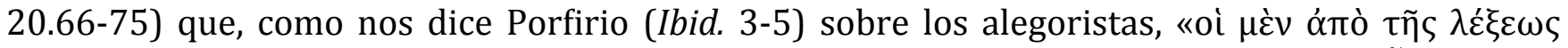

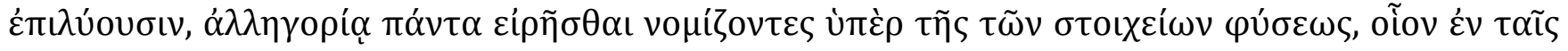
$\varepsilon \dot{\varepsilon} v \alpha \nu \tau \iota \omega ́ \sigma \varepsilon \sigma \iota \tau \tilde{\omega} v \theta \varepsilon \tilde{\omega} v »$ (ellos desde el discurso explican creyendo decir todas las cosas sobre la naturaleza de los elementos en alegoría, tal como en las oposiciones de los dioses). He aquí el pasaje homérico: ${ }^{15}$

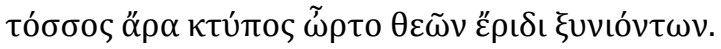

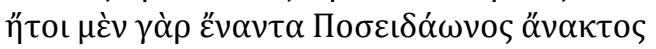

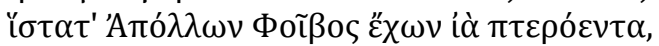

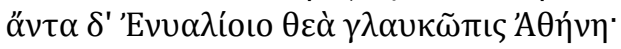

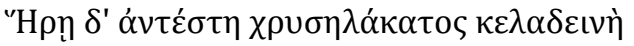
"А
} 


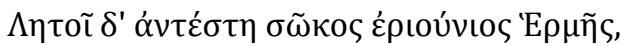

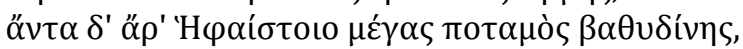

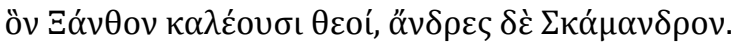

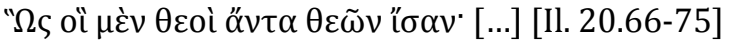

«Tal estrépito, claro, urgió a la disputa entre los dioses participantes.

Por cierto, pues, frente al soberano Poseidón

se paró Febo Apolo teniendo saetas aladas,

frente a Enialio la diosa de ojos glaucos, Atenea.

A Hera enfrentó a la de rueca de oro, la sonante

Ártemis sagitaria, hermana del flechador.

$\mathrm{Y}$ a Leto se enfrentó el fuerte Hermes benéfico,

y, claro, frente a Hefesto el gran río, profundo,

al que los dioses llaman Janto y los varones Escamandro.

Y así los dioses se enfrentaban a los dioses. [...]» ${ }^{16}$

La lectura en clave alegórica de Teágenes propone interpretar este pasaje como un choque de las fuerzas cósmicas en la forma de elementos primordiales o conceptos abstractos metafísicos de un universo en continuo movimiento. Los opuestos de agua-fuego, mar-cielo, vejez-juventud se representan en el enfrentamiento entre Poseidón y Apolo. Por su parte, Ares (Enialio) expresa el sentimiento de lujuria y locura por la batalla frente a la presencia de la sabiduría (también guerrera) en la forma de Atenea. Hera constituye el símbolo del éter y Ártemis de la luna, lo doméstico se enfrenta a lo salvaje, lo inmóvil a lo móvil. El olvido, la léthe (Leto) ${ }^{17}$ se opone al lógos (Hermes), el fuego de Hefesto nuevamente al agua representada en río (Janto / Escamandro). ${ }^{18}$ PseudoLongino (9.7.1-2) comenta que para que este pasaje no sea algo absurdo y escandaloso debe interpretarse de modo alegórico, puesto que hacerlo de modo literal no sería conveniente

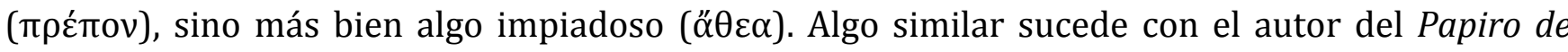
Derveni que propone una interpretación alegórica en torno a las creencias tradicionales que pueden resultar inverosímiles o inaceptables si se alude a ellas de modo literal (Janko 2001, p. 2). Por su parte, Porfirio nos dice además que «Ciertamente este modo de apología es en verdad antiguo, viniendo desde lejos, de Teágenes de Regio, el primero que escribió sobre

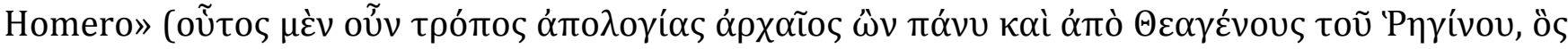
$\pi \rho \tilde{\omega} \tau \alpha \varsigma$ है $\gamma \rho \alpha \psi \varepsilon \pi \varepsilon \rho \grave{~ ' O \mu \eta ́ p o u) ~(P o r f ., ~ Q u a e s t . ~ H o m . ~ I l . ~ 20.67 .16-18 ; ~ T h e a g . ~ F r . ~ 2.13-14) .19 ~ P o r ~ o t r o ~}$ lado, no parece ser casual que, justo en el pasaje homérico sobre el que la alegoría resulta más productiva, el poeta aluda a la distinción de dos planos del lenguaje, a saber, uno para el ámbito divino y otro para el ámbito humano. Ello no constituye, no obstante, una correspondencia uno a uno (plano divino/humano) con la interpretación alegórica. Es decir, no implica que lo humano se corresponda con lo «literal» y lo divino con lo «alegórico» o viceversa. Simplemente exhibe la posibilidad de enunciar lo mismo desde niveles y modos diferentes en lenguajes distintos: esto es lo que sucede con la alegorización. Por lo tanto, esta distinción implica al menos dos niveles de enunciación del objeto distintos y ambos intrínsecos a él.

Prima facie la lectura de Teágenes implicaría una traducción directa del pasaje homérico en nociones propias de un periodo que comienza a buscar la explicación del universo en elementos materiales. El alegorista muestra, no obstante, que estos conceptos ya se encuentran presentes en la poesía homérica bajo la figura de los dioses: hay una correspondencia directa entre las divinidades y los elementos de la naturaleza que los filósofos presocráticos proponen como 
principios explicativos del universo. Se trata de una estructura racional como sistema explicativo que se plasma en un lenguaje épico-poético que debe decodificarse en los conceptos propios de la filosofía de la naturaleza. ${ }^{20}$

\section{FERÉCIDES DE SIROS}

Según Diógenes Laercio, Ferécides fue el primer griego en escribir sobre la naturaleza y sobre los dioses mediante el lógos (Vid. 1.116.3-4, 1.43.1-2). En el clásico artículo "The Beginnings of Greek Allegory", Tate (1927) sostenía que las contribuciones de Teágenes a la llamada «interpretación alegórica» habían sido exageradas y que el verdadero pionero de esta forma de abordaje de los textos homéricos había sido Ferécides de Siros. Sin embargo, Schibli (1990, pp. 99-100) ha advertido sobre la complejidad de ubicar a Ferécides como un alegorista y algunos de sus problemas. ${ }^{21}$ Sin entrar en la discusión en torno a la preeminencia de uno sobre otro o su título de «alegorista», «poeta» 0 «filósofo», lo cierto es que Aristóteles en Metafísica (1091b) alude a aquellos poetas antiguos que sostenían que el universo estaba regido y gobernado por Zeus y no por las divinidades y elementos primordiales como Caos u Océano entre otras, y allí mismo el Estagirita pone el ejemplo de Ferécides de Siros, quien habría mezclado el tipo de explicación mítica con aquella que él propone como estrictamente filosófica; un modo de pensamiento alcanzado a través de una síntesis entre filosofía y mito (Met. 1091b8). El contexto del pasaje aristotélico refiere a la búsqueda de los primeros principios por parte de sus predecesores para luego exponer su posición metafísica al respecto. Una de las alusiones más directas a la alegórisis de Ferécides puede verse en la siguiente cita sobre sobre su interpretación de la poesía homérica (7 B 5 DK):

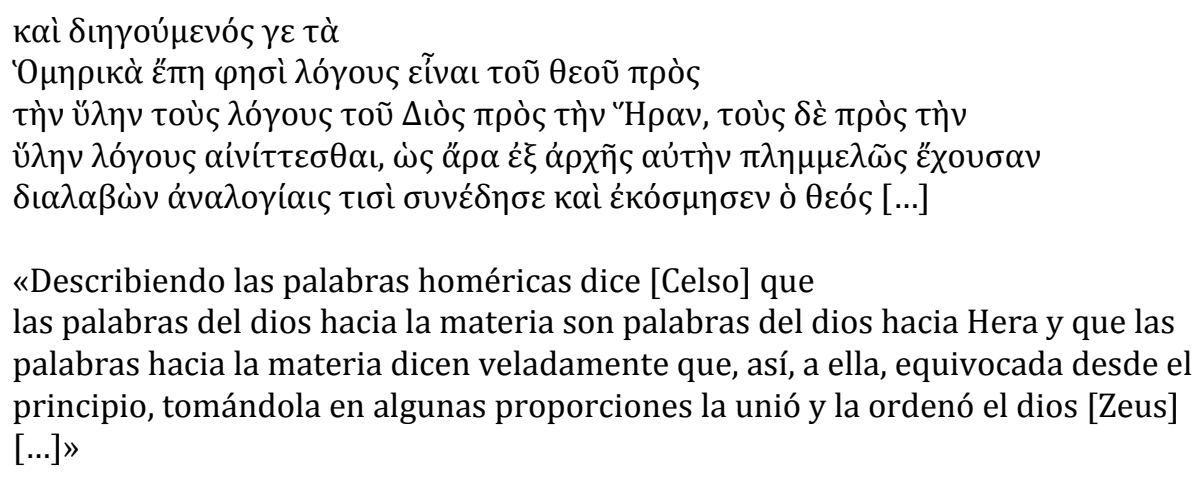

Este testimonio hace referencia a una, aparentemente, conocida lectura de Ferécides a unos versos homéricos (Il. 1.590, 15.18-33). ${ }^{22}$ Semejante a la alegórisis de Teágenes, nuevamente los dioses vienen a representar elementos naturales del orden cósmico. Las palabras de Zeus a Hera son palabras del dios a la materia desordenada con las que se pretende sintetizarla proporcionadamente en una unidad, al mismo tiempo que el dios supremo se presenta como una potencia divina que puede asociarse a una inteligencia cósmica ordenadora. Según este testimonio, Ferécides sostenía que esto es algo que la épica homérica formula, aunque de modo oscuro o

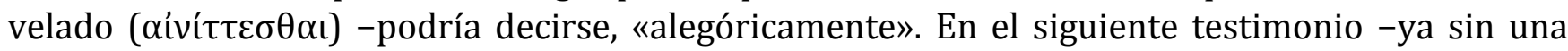
alusión a un pasaje específico de la épica- encontramos a los dioses primordiales (según la cosmogonía de Ferécides) como principios explicativos (7 A 9 DK): 


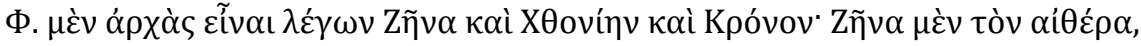

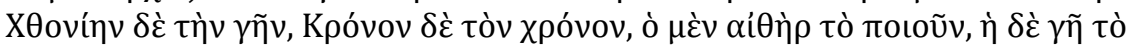

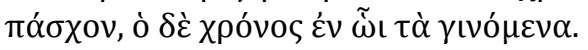

«Ferécides dice que los principios son Zeus, Chthonia y Cronos. ${ }^{23}$ Así, Zeus es el éter, Chthonia es la tierra y Cronos el tiempo. El éter es el que actúa, la tierra es

la actuada y el tiempo es en donde las cosas devienen.»

Los dioses se identifican no tanto con los elementos materiales de la naturaleza, sino más bien con una estructura cósmica cuyos principios establecen la puesta en acto ( $\pi \circ \circ \# v)$ del universo. En Ferécides las identificaciones etimológicas Cronos/Chrónos y Zeus/Zas (también por alusión y contexto análogo Okeanós/Ogenós, 7 B 2 DK; y conceptualmente, Chthónia/Gé) refuerzan el sentido de la interpretación alegórica en el que los dioses originadores del universo y sus funciones se transmutan en principios explicativos de la dinámica del orden cósmico: el éter, la tierra y el tiempo. También se ha señalado que la doble nomenclatura puede tener origen en la división de un lenguaje para los dioses y otro para los hombres operada en los poemas

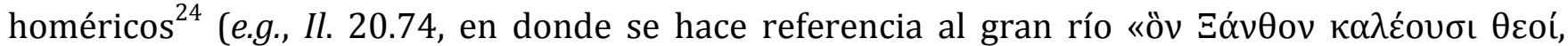

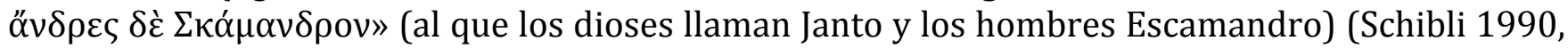
p. 67). Por otro lado, como señala Lisi (1985, p. 266), la teogonía presentada por Ferécides se separa de Homero y Hesíodo -además de postular una tríada divina diferente a la de los poetas

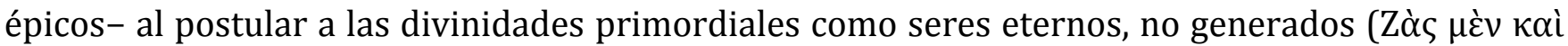

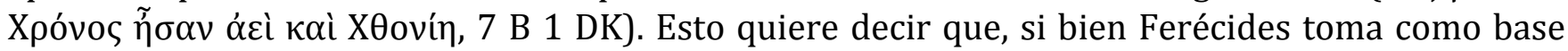
para su propuesta filosófica a la épica y traduce, a su vez, muchos de sus términos a un lenguaje propio, su trabajo no constituye una mera exégesis del texto homérico sino, en todo caso, un diálogo filosófico con Homero en torno a las cuestiones metafísicas de un clima de época. Así, el tono del siguiente fragmento evoca el lenguaje característico de los «fisiólogos» del siglo VI a.C., pero partiendo de premisas míticas (7 B 3 DK):

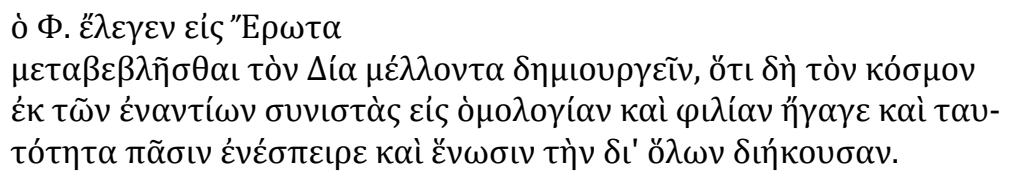

A partir de esta cita las palabras de Aristóteles (Met. 1091b8) de que las ideas de Ferécides constituían una suerte de síntesis entre filosofía y mito adquieren toda su inteligibilidad. Se parte de un trasfondo cultural compartido que el autor modifica y reformula orientando el escenario y los personajes míticos hacia ideas filosóficas de cuño milesio. La necesidad de la transmutación de Zeus en Eros implica la necesidad de mantener la posición predominante de Zeus en el orden cósmico, como se da en el mito tradicional y, al mismo tiempo, dotarlo de una potencialidad causal -presente particularmente en Eros como fuerza activa- que pueda operar como principio explicativo de la totalidad. Asimismo -y distanciándose tanto de Homero como de Hesíodo-, se presenta a Zeus como un demiurgo creador del universo; una novedad que también puede advertirse en las bodas de 


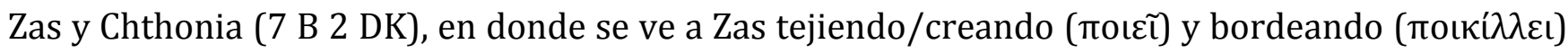
un paño de tela ( $\varphi \tilde{\alpha} \rho \circ \varsigma)$ que representa al dios supremo como un artesano cósmico que opera inteligentemente como causa, diseño y orden del mundo. Según Clemente de Alejandría (Str. 6.2.8.9) Ferécides habría construido el episodio de las bodas de Zas y Chthonia a partir de Il. 18.483-607, en donde el poeta, por medio de la ékphrasis del escudo del Aquiles, representa el cosmos, en el que la tierra, el cielo y el mar, el sol, la luna, junto con todos los astros, forman el firmamento en su totalidad. ${ }^{25}$

Con todo, se observan en Ferécides algunos componentes debidamente articulados: se presentan como punto de partida el mito tradicional y contexto cultural compartido con sus eventuales reformulaciones y algunos pasajes homéricos y, como resultado, las ideas filosóficas predominantesen la época del autor. A partir de los testimonios conservados puede verse un intento no solo de traducir el lenguaje mitológico tradicional, y particularmente la épica homérica, a las nuevas formas de expresión filosóficas del siglo VI a.C., sino también establecer una continuidad y filiación conceptuales entre estos.

\section{METRODORO DE LÁMPSACO}

Diógenes Laercio (Vid. 2.11.7-8) nos dice que fue Metrodoro de Lámpsaco, discípulo de

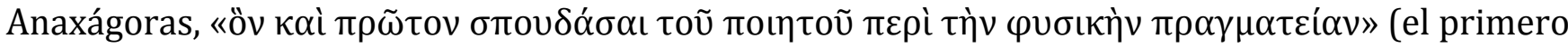
en estudiar del poeta lo relativo a la cuestión de la física). Platón (Ion, 530c7-d3) constituye el primer testimonio conservado de Metrodoro y, como se ha señalado anteriormente, habla de él como uno de los comentadores de los poemas homéricos. A pesar de los escasos testimonios conservados de Metrodoro y los otros alegoristas, puede afirmarse que una de las singularidades de este filósofo presocrático, además de alegorizar los pasajes homéricos en torno a los dioses como fuerzas y fenómenos naturales, es que sumó a la alegórisis a los héroes de la épica. Según se nos dice, Metrodoro (61 A 4 DK) afirmó que:

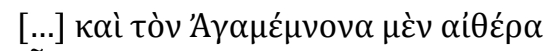

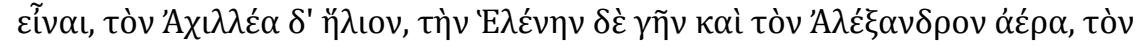

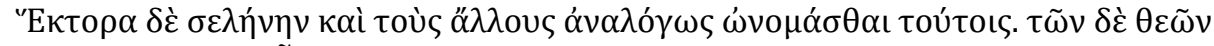

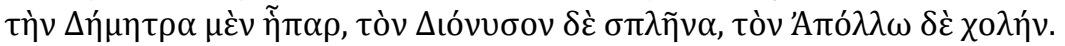

«[...] por un lado, Agamenón es el éter y por otro Aquiles es el sol; Helena es la tierra y Alejandro el aire, Héctor es la luna y los demás se llaman análogamente a estos. Pero entre los dioses Démeter es el hígado, así como Dionisio es el bazo y Apolo la bilis.»

Los elementos del universo ya no se corresponden con los dioses como en el caso de Teágenes y Ferécides, sino que son los héroes de la épica quienes ahora se identifican directamente con estos elementos primarios del orden natural. Asimismo, los dioses se identifican con partes del cuerpo humano sobre las que podría pensarse en algún tipo de significación de orden moral. De este modo, los héroes homéricos constituirían la representación de las sustancias elementales del macrocosmos, mientras los dioses figurarían la imagen del microcosmos humano en esta expresión de la totalidad del universo (Califf 2003, p. 30). Las identificaciones de Metrodoro no son etimológicas (como en el caso de Teágenes o Ferécides), así como tampoco se sitúan como episodios 
aislados dentro del poema, disociados de su trama central. Más bien constituirían relaciones estructurales entre elementos que operan en distintos niveles narrativos como dos caras de una misma moneda. Parece haber en Metrodoro un compromiso más fuerte con la perspectiva global del poema y su narrativa. De modo que Helena, siendo el núcleo sobre el que se desarrolla la guerra de Troya, puede identificarse con la tierra que se ubica en el centro del universo y que al mismo tiempo, como en el sistema de Anaxágoras, -según la tradición, su maestro- es abrazada

por el aire ${ }^{26}$ (Paris) (Richardson 1975, p. 69). Aquiles puede identificarse con el sol no solo por una interpretación "añadida» del alegorista, sino a través de las mismas palabras del poeta. Así, además de las clásicas identificaciones entre Aquiles y Apolo y este con el sol -junto con el ardor y la cólera del héroe que atraviesa todo el poema con el que fácilmente puede asociarse el sol-, el

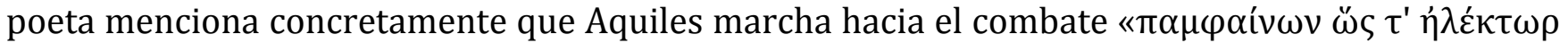

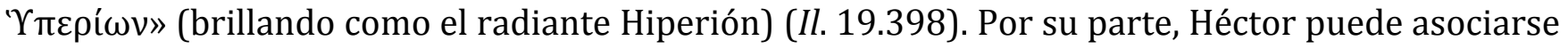
a la luna si se piensa en la luz de su fama que en gran medida es provista por Aquiles (sol), e incluso puede comprenderse a los mejores héroes en el marco de los símiles sobre los astros y el fuego (Scott 1974, p. 66). En el caso de la identificación entre Agamenón y el éter la situación no es tan explícita y directa. Sin embargo, en la mayoría de los pasajes de la Ilíada en donde aparece el éter este es vinculado al espacio de Zeus ${ }^{27}$-además de la explícita alusión a la repartición de las partes del cosmos entre Zeus, Poseidón y Hades en donde el poeta dice que "Zcùs $\delta$ ' '̌̉ $\lambda \alpha \chi^{\prime}$

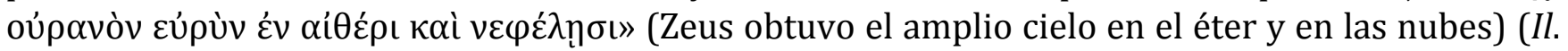
15.192) - y es clara la filiación entre Agamenón y Zeus por medio de la herencia del cetro divino (Il. 2.100-108). Además, si se piensa en el éter como lo más alto y supremo del ámbito divino, Agamenón puede ser pensado como el poder más elevado del ámbito humano. Por supuesto, pueden establecerse relaciones más complejas y profundas entre la interpretación alegórica de Metrodoro y los poemas homéricos como un todo coherente y armónico, pero no es el objeto de este artículo ya que una tarea semejante amerita un trabajo más minucioso y de mayor profundidad. Lo que vale señalar en este caso es la inserción de Metrodoro en la corriente alegórica y al mismo tiempo marcar su singularidad con respecto a los alegoristas precedentes.

Por otro lado, sabemos a través de las palabras de Jenófanes, uno de los primeros críticos de la

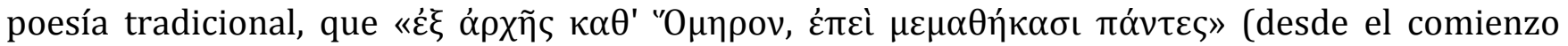
todos han aprendido sobre Homero) (21 B 10 DK). De modo que este abordaje que Metrodoro realiza sobre la poesía homérica explícitamente para elaborar sus doctrinas filosóficas probablemente haya estado en la estructura filosófica, consciente o inconscientemente, de los pensadores presocráticos y posteriores, aunque no siempre de modo explícito. ${ }^{28}$ A continuación se trazarán algunos puntos de partida de este enfoque.

\section{FILIACIONES ALEGÓRICAS ENTRE LOS FILÓSOFOS PRESOCRÁTICOS}

Mucho se ha discutido en torno a la herencia o dependencia del pensamiento de los filósofos presocráticos con respecto a la tradición mitológica. ${ }^{29}$ Sin adentrarnos en una temática que es de por sí un tópico de investigación en sí mismo, pueden al menos trazarse someramente algunas notas generales con respecto a la filiación de la llamada «filosofía presocrática» y la interpretación alegórica -si es que puede establecerse una verdadera dicotomía entre ambas esferas. Así, con el maestro de Metrodoro, Anaxágoras, puede advertirse tenuemente una identificación entre Zeus y el 
noûs (59 A 20c DK), exhibiendo cierto bagaje mitológico que sirve de base para la conformación de la estructura cosmológica de su filosofía. Esto se observa más claramente en el caso de Empédocles. El filósofo, para ofrecer una respuesta a la teoría monista de los eleatas (Parménides), propone cuatro divinidades como representantes de los cuatro elementos: Zeus, Hera, Aidoneo y Nestis (31 B 6 DK); Fuego, Aire, Tierra y Agua (B 17, A 33), así como también a Eros (Philía o Afrodita) y Lucha (Neikós) (B 16, B 22), ${ }^{30}$ como los principios explicativos del universo, recurriendo de este modo nuevamente al lenguaje mitológico. Por supuesto, Empédocles le da su impronta a su propia cosmovisión en donde no hay una jerarquía divina, probablemente a raíz de pensar los términos metafísicos del cosmos como fundamento del microcosmos político de su contexto democrático, que el filósofo de Acragas pretendía defender al postular la igualdad de los primeros elementos. Como puede advertirse, en términos generales y partir de estos conceptos, la filosofía de Empédocles puede entenderse como una mezcla entre, por un lado, el tipo de explicación alegórica -no ya remitiendo a los poemas homéricos de modo explícito y directo, pero sí sobre las fuerzas divinas omnipresentes en un contexto mítico culturalmente compartido- y, por otro, el lenguaje imperante durante el siglo VI a.C. (con una relativa intención de desvincularse del ropaje mítico personificado).

Con respecto a la escuela milesia, como señala Domaradzki (2011, p. 217), paralelos entre los filósofos presocráticos como Tales, Anaximandro, Anaxímenes (incluido Jenófanes) y los primeros alegoristas difícilmente puedan deberse a la mera casualidad. Si bien es probable que conocieran sus ideas mutuamente, es más verosímil pensar en la continuación de la tradición cosmológica -iniciada por los primeros poetas- en el marco de un lenguaje y clima de época, puesto que la tendencia a hablar en alegorías no es un uso exclusivo de los llamados «alegoristas». Ahora, sostener que esta pretensión de independización de la personificación mítica para la elaboración cosmológica ya comenzaba a darse en los primeros presocráticos a principios del siglo VI a.C. en un proceso evolutivo hacia formas más «racionales» del pensamiento filosófico -como señala Domaradzki - no permite incluir a Empédocles en tal categorización, a menos que hable de una involución de dicho proceso. Es por ello que una perspectiva racionalista evolutiva no resulta apropiada para abordar la cuestión en torno a las postulaciones filosóficas en forma de mito, alegorías o propuestas aparentemente secularizadas.

Ahora bien, aunque en la mayoría de los filósofos presocráticos la filiación con alegorización no siempre se realiza de un modo explícito -al menos a partir de los testimonios conservados-, es difícil sostener que tal coincidencia conceptual se deba a la casualidad, más aún si se piensa en la continuidad cultural documentada entre los poemas homéricos y los filósofos del siglo VI a.C. (el caso de Jenófanes sea tal vez uno de los más ilustrativos). En tal caso, si se aplica el mismo modo de argumentación de Seaford (2004) -en donde la monetarización en el sentido peculiar que el autor afirma que se da en Grecia de un modo inédito es la condición de posibilidad para la generación de la forma mentis de los griegos con su posterior desarrollo en el ámbito de la filosofía, el arte y la política- es lícito pensar que la cosmovisión metafísica de los poemas homéricos sienta las bases del pensamiento de los llamados «filósofos de la naturaleza». No obstante, no se trata de un mero esbozo o anticipación que luego sería retomado por los presocráticos, algo ya enunciado por Aristóteles entre otros (Met. 1074b). Las explicaciones filosóficas alegóricas constituyen un uso pura y esencialmente filosófico del mito. Los pocos testimonios en torno a la interpretación alegórica exhiben a los filósofos arcaicos en un diálogo con Homero sin solución de continuidad -no solo como defensores o meros exégetas del poeta- con tensiones, apropiaciones y rupturas dentro de sus propios sistemas filosóficos. 


\section{LA INTERPRETACIÓN ALEGÓRICA: ¿EXÉGESIS FILOSÓFICA O MERA APOLOGÍA?}

Al comienzo de este trabajo se ha hecho referencia a la tesis que sostiene que la interpretación alegórica surge como una defensa filosófica frente a los embates críticos contra ciertas inadecuaciones de los poemas homéricos. Si bien esto es correcto para el periodo helenístico ${ }^{31}$ pareciera ser necesario relativizarlo en el periodo arcaico. Resulta llamativo que, en el examen sobre los diferentes métodos para defender a los poetas de las críticas espurias, Aristóteles (Poét. 1460b36-61a1) no incluya la alegórisis (Ford 2002, p. 69). Tampoco Platón (Ion, 530d), al referirse a los llamados «alegoristas», habla de una defensa de su parte sino más bien de un «ordenamiento»

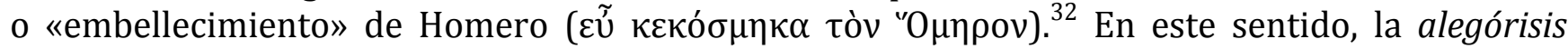
épica no inventó un nuevo método de leer a Homero, sino que, en rigor, transfirió la épica a un discurso ya establecido con su propio lenguaje y pautas de decodificación. Si bien no puede negarse de modo absoluto cierto carácter apologético de la interpretación alegórica, es más adecuado pensar en un uso relegado a aquellos capaces de leer a Homero «apropiadamente» frente a quienes no logran entender su verdadero sentido. ${ }^{33}$

En efecto, la interpretación alegórica en su faceta original no debe entenderse como una exégesis apologética en el mismo sentido que se da de modo paradigmático en el periodo helenístico. La alegórisis arcaica puede, en todo caso, considerarse un puente o, en cierta medida, ese eslabón perdido que muchas veces se ha sustituido por surgimientos ex nihilo de los pensadores jónicos orientados hacia una filosofía de la naturaleza. Aunque conservamos una porción muy ínfima de sus tratados, la escasa evidencia sugiere que este modo de interpretar los poemas homéricos no crea un texto nuevo a partir de una interpretación «añadida», sino que, más bien, decodifica los términos de un ámbito filosófico al lenguaje propio de un periodo particular en donde ciertos tópicos específicos -existentes ya en los poemas homéricos pero confundidos (para las masas) en el lenguaje poético de la épica- comienzan a tener un tratamiento independiente. El punto es: tanto Homero como los presocráticos se refirieron a los mismos asuntos, pero en idiomas diferentes. En tal caso debe tenerse en cuenta la importancia de las demandas del auditorio homérico y, en efecto, el condicionamiento al momento de entonar el canto, como puede verse en la censura a Femio

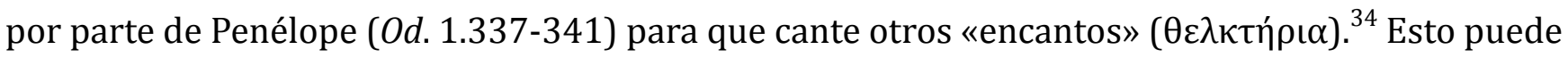
sugerir que no solo habría un condicionamiento con respecto al contenido, sino también a la forma o género como instrumento para su formulación. Si pensamos en el canto épico como el vehículo de transmisión del conocimiento por antonomasia, es lógico que el pensamiento filosófico se haya desplegado en forma de poesía, con sus propias reglas, herramientas, vocabulario y lenguaje.

Esta mirada sobre la poesía homérica en torno a la transmisión del conocimiento de múltiples disciplinas mediante el canal del lenguaje poético-mitológico de los poemas homéricos no es ajena

a la Antigüedad. ${ }^{35}$ Las palabras de Pseudo-Plutarco (De Hom., 41-43, 48-53) pueden ilustrar este enfoque al afirmar sobre Homero que:

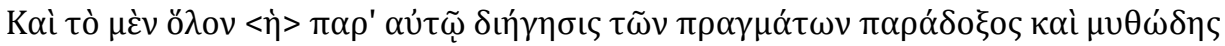

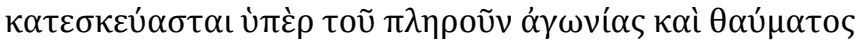

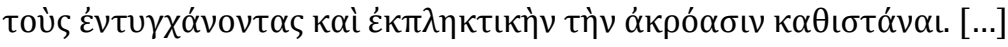
(41-43) 


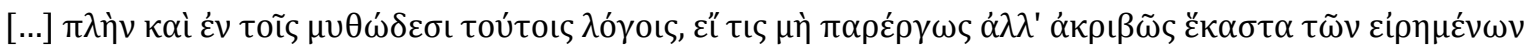

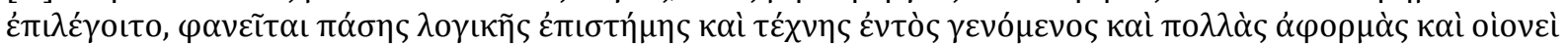

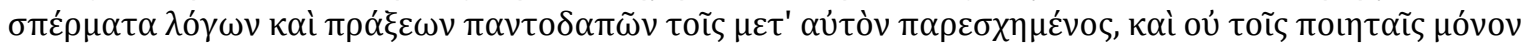

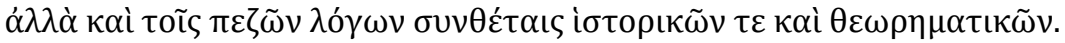

(48-53)

«En términos generales, en él la narración de los hechos se construye de forma paradójica y mítica para llenar de ansiedad y asombro a los lectores y colocar sobre la audiencia estupefacción. [...] Por otra parte, incluso en estos discursos míticos, si alguien, no someramente sino con exactitud, hablara en conexión con cada una de las cosas dichas, se mostrará que el resultado dentro de toda ciencia racional y arte ha procurado muchos puntos de partida, así como semillas de palabras y hechos de todo tipo junto a ellos en cuanto a lo mismo, y no solo para los poetas sino también autores de discursos prosaicos, historiográficos y teóricos.»

Como puede advertirse, el acento está puesto nuevamente en el modo de enunciación y en la necesidad de un tipo de discurso y vocabulario para la demanda de una determinada audiencia y ocasión. Es claro que en los comienzos del periodo arcaico la prosa y el lenguaje de los siglos VI y V a.C. no podría ofrecer las mismas garantías de difusión que el lenguaje poético de la épica. De modo que, para la época arcaica al menos, la epopeya constituye el vehículo transmisión por antonomasia de cualquier disciplina o forma de conocimiento. En este sentido se orientan las palabras de Pseudo-Plutarco al reafirmar a Homero como el iniciador no solo de muchos tópicos que los poetas han retomado, sino incluso de un saber que para la época del comentador aún una forma de conocimiento científico, sin dejar de constituir al mismo tiempo un discurso mítico.

\section{CONCLUSIONES}

Se han presentado los puntos fundamentales de la interpretación alegórica de los poemas homéricos en el periodo arcaico a través de los testimonios de los alegoristas Teágenes, Ferécides y Metrodoro, exhibiendo también el trasfondo alegórico que puede advertirse en la filosofía presocrática, como se ha visto en el caso de algunos de los llamados «filósofos presocráticos», y señalando someramente el modo en que algunas nociones filosóficas del texto homérico subyacen a determinadas conceptualizaciones ontológicas o discursivas. A partir de la escaza evidencia sobre estos alegoristas, se ha visto en Teágenes una alegórisis más «lineal», en una correspondencia directa entre los dioses y los elementos primordiales, así como también sus asociaciones etimológicas. En Ferécides hay más bien una reformulación y apropiación de las etimologías dentro de su propio sistema teogónico. A partir de ello, y tomando como premisas de su sistema filosófico tanto el mito tradicional en general, como episodios homéricos en particular, Ferécides esboza los conceptos filosóficos del periodo como un resultado de dicha formulación teogónica. Por último, Metrodoro no se centra en las asociaciones etimológicas entre dioses y elementos, así como tampoco traza correspondencias conceptuales entre ellos. En el hombre de Lámpsaco la identificación se da entre los héroes de la épica homérica y los elementos, ya no como un episodio alegórico aislado, sino en una coherencia holística dentro de la trama de los poemas. En efecto, al menos en lo que respecta al periodo arcaico, la alegórisis no debe entenderse como un mero discurso apologético, así como tampoco como una interpretación añadida. Más bien se trata de una decodificación de determinadas nociones propias de la esfera filosófica enmarcadas en el ámbito épico. Esto sugiere cierta continuidad y filiación que se establece entre la filosofía presente en los poemas homéricos expresada en un lenguaje épico-poético y la filosofía presocrática con su 
estilo y características propias. Así, la interpretación alegórica vislumbra el carácter profundamente filosófico de los poemas homéricos, situándolos en los albores de la historia de la filosofía griega como un punto de partida en un ininterrumpido camino dialógico sobre ella y prefigurando el modo de explorar determinadas cosmovisiones de los siglos VI y V a.C.

\section{Bibliografía}

Abritta, A., et al., Ilíada: Canto 1. Traducción comentada. Segunda edición, ampliada y corregida, Buenos Aires: http://www.iliada.com.ar, 2020.

Allen T. (ed.), Homeri Ilias 2-3, Oxford: Clarendon Press, 1931.

Alesso, M. H., Interpretación alegórica de los textos homéricos en el siglo I: Heráclito el rhetor. Alegorías de Homero, Universidad Nacional de La Plata, Facultad de Humanidades y Ciencias de la Educación, 2001.

Bernabé Pajares, A., "La Teogonía Órfica del Papiro de Derveni”, Arys (1999), 301-338.

Bernabé Pajares, A., "The Derveni Papyrus: Problems of Edition, Problems of Interpretation," en Gagos, T. (ed.), Proceedings of the 25th International Congress of Papyrology, 2007, Ann Arbor, 2010, 77-83.

Buffière, F., Les Mythes d'Homère et la pensèe grecque, Paris: Les Belles Lettres, 1956.

Buffière, F., (ed.) Héraclite. Allégories d'Homère, Paris: Les Belles Lettres, 1962.

Burnet, J. (ed.), Platonis opera 1-5, Oxford: Clarendon Press, 1:1900; 2:1901; 3:1903; 4:1902; 5:1907.

Califf, D., "Metrodorus of Lampsacus and the problem of allegory: an extreme case?", Arethusa 36, 2003, 21-36.

Cassin, B., "Sobre algunas escenas filosóficas primitivas en Homero”, en Cordero (ed.), El filósofo griego frente a la sociedad de su tiempo, Buenos Aires: Rhesis, 2013, pp. 54-65.

Chantraine, P., Dictionnaire étymologique de la langue grecque. Histoire des mots, Paris: Klincksieck, 1968.

Curd, P., "On the Question of Religion and Natural Philosophy in Empedocles", Perris (2005), 137-162.

Diels, H. y Kranz W. (eds.), Fragmenta, Die Fragmente der Vorsokratiker 1-3, 6th edn. Berlin: Weidmann, 1952.

Domaradzki, M., "Theagenes of Rhegium and the rise of the allegorical interpretation", Elenchos 32 (2011), 205-227.

Emlyn-Jones, C. J., The Ionians and Hellenism: A Study of the Cultural Achievement of Early Greek Inhabitants of Asia Minor, London, Routledge, 1980.

Feeney, D., The Gods in Epic, Oxford, 1991.

Finkelberg, M., “Oral Formulaic Theory and the Individual Poet”, en Montanari, F., Rengakos, A., Tsagalis, C. (eds.), Homeric Contexts. Neoanalysis and the Interpretation of Oral Poetry, Berlín: De Gruyter, 2012, pp. 73-82.

Ford, A., The Origins of Criticism, Princeton, NJ, 2002.

Goodspeed, E. J. (ed.), Oratio ad Graecos. Die ältesten Apologeten, Göttingen: Vandenhoeck \& Ruprecht, 1915, 268-305.

Graziosi, B., Inventing Homer: The Early Reception of Epic, Cambridge: Cambridge University Press, 2002.

Hilgard, A., Scholia in Dionysii Thracis. Artem Grammaticam, Olms, 1965.

Hunter, R., The Measure of Homer. The Ancient Reception of the Iliad and the Odyssey, Cambridge, 2018.

Janko, R., “The Derveni Papyrus. A New Translation”, CP 96 (2001), 1-32.

Kassel, R., (ed.), Poetica, Aristotelis de arte poetica liber, Oxford, Clarendon Press, 1965.

Kindstrand J. F. (ed.), Plutarchi. De Homero 2, Leipzig: Teubner, 1990, 7-117. 
Kirk G. S., Raven J. E. y Schofield, M., Los filósofos presocráticos. Historia crítica con selección de textos, Madrid, Gredos, 1983 [1957].

Latacz, J., Troya y Homero. Hacia la resolución de un enigma, Barcelona: Destino, 2001.

Liddell H. G.; Scott R.; Jones H. S.; Mckenzie R. (9ae ed. revisada), A Greek English Lexicon, Oxford, Clarendon Press (1a ed. 1819), 1996.

Lisi, F., “La teología de Ferécides de Siros”, Salamanca: Helmántica 36 (1985), 251-276.

Nagy, G., Homeric Questions, University of Texas, 1996.

Nünlist, R., The Ancient Crtitic at Work. Terms and Concepts of Literacy Criticism in Greek Scholia, Cambridge, 2009.

Palmer, J., "The World of Early Greek Philosophy”, en Sheffield, F., Warren, J., (eds.), The Routledge Companion to Ancient Philosophy, Routledge, 2014, pp. 54-87.

Pfeiffer, R., History of Classical Scholarship: From the Beginnings to the End of the Hellenistic Age, Oxford: University Press, 1968.

Prada, G. A., La filosofía de Homero. Sobre ciertos problemas y perspectivas de filosofía política en Ilíada y Odisea, http://repositorio.filo.uba.ar/handle/filodigital/4506, 2018.

Primavesi, 0., "Empedocles: Physical and Mythical Divinity", en The Oxford Handbook of Presocratic Philosophy, Patricia Curd y Daniel W. Graham (eds.), Oxford: Oxford University Press, 2009, pp. 250-283.

Richardson, N. J., "Homeric Professors in the Age of the Sophists”, PCPS 21, 1975, 65-81.

Ross, W. D. (ed.), Aristotle's metaphysics, 2 vols, Oxford: Clarendon Press, 1924.

Schironi, F., The Best of the Grammarians, University of Michigan Press, 2018.

Schrader, H. (ed.), Quaestionum Homericarum ad Iliadem pertinentium reliquiae, fasc. 1-2. Leipzig: Teubner, 1880-1882.

Scott, W. C., The Oral Nature, of the Homeric Simile, Leiden: Brill, 1974.

Seaford, R., Money and Early Greek Mind. Homer, Philosophy, Tragedy, Cambridge, 2004.

Schibli, H., Pherekydes of Syros, Oxford: Clarendon Press, 1990.

Shackleton Bailey, D. R. (ed.), M. Tullius Cicero. Epistulae ad Atticum 6 vols., 1965-1968.

Svenbro, J., La parole et le marbre. Aux les origines de la poétique grecque, Lund, 1976.

Tate, J., "The Beginnings Of Greek Allegory," Classical Review 41 (1927), 214-215.

Thibau, R., "Le bouclier d'Achille”, en Decreus F. (ed.), Hommages à Jozef Veremans. Collection Latomus 193, Bruxelles, Latomus, 1986, 299-307.

Torres, D., La escatología en la lírica de Píndaro y sus fuentes, Universidad de Buenos Aires, 2007.

Tsantsanoglou, K., "The First Columns of the Derveni Papyrus" and their Religious Significance" en Lacks, A. y Most, G. W. (eds.), Studies on the Derveni Papyrus, 1997, pp. 93-128.

Van der Valk M. (ed.), Commentarii ad Homeri Iliadem. Eustathii archiepiscopi Thessalonicensis commentarii ad Homeri Iliadem pertinentes, vols. 1-4, Leiden: Brill, 1:1971; 2:1976; 3:1979; 4:1987.

Van Thiel, H. (ed.), Homeri Odyssea, Olms-Weidmann, 1991.

Versényi, L., Man's Measure: A Study of the Greek Image of Man from Homer to Sophocles, Albany, State University of New York Press, 1974.

West, M. L., The Orphic Poems, Oxford, 1983. 
1 Este tipo de interpretación se ha realizado sobre varios poetas de la Antigüedad (J. Palmer, "The World of Early Greek Philosophy", en Sheffield, F., Warren, J., (eds.), The Routledge Companion to Ancient Philosophy, Routledge, 2014, pp. 52-53, e.g., para el caso del poema de Parménides).

2 Sin adentrarme en la cuestión homérica, aquí se toma a «Homero» como nombre técnico para referirse al compositor de la llíada y la Odisea (Cfr. M. Finkelberg, "Oral Formulaic Theory and the Individual Poet", en Montanari, F., Rengakos, A., Tsagalis, C. (eds.), Homeric Contexts. Neoanalysis and the Interpretation of Oral Poetry, Berlín: De Gruyter, 2012, pp. 73-82; J. Latacz, Troya y Homero. Hacia la resolución de un enigma, Barcelona: Destino, 2001; G. Nagy, Homeric Questions, University of Texas, 1996). En el caso de los alegoristas -y en los antiguos en general- es complejo de determinar si «Homero» se utiliza para designar a un poeta en particular, autor exclusivamente de los dos grandes poemas, o de toda la épica en general. Para un estudio sobre la significación de Homero en la Antigüedad, B. Graziosi, Inventing Homer: The Early Reception of Epic, Cambridge: University Press, 2002.

3 Para una interpretación de los poemas homéricos desde una perspectiva filosófica y como el inicio de la historia de la filosofía, G. A., Prada, La filosofía de Homero. Sobre ciertos problemas y perspectivas de filosofía política en Ilíada y Odisea, http://repositorio.filo.uba.ar/handle/filodigital/4506, 2018.

4 Es el enfoque moderno el que ha categorizado a la crítica de Jenófanes como una objeción al antropomorfismo de los dioses cuando, en rigor, para los antiguos lo objetable de la representación tradicional de los dioses es más bien su antropopatía (D. Feeney, The Gods in Epic, Oxford, 1991, p. 48).

5 E.g. Rep. 386a-404c, Ley. 656a-664a.

6 Esto es algo que, sin duda, sucede con los gramáticos alejandrinos, cuyos escolios, en efecto, entre otras cosas, tuvieron diversos usos y propósitos, desde la exégesis filosófica o una función apologética para justificar al poeta encumbrando así el concepto de licentia poetica, hasta la conciliación y armonización entre la mitología divina pagana y la cultura cristiana. Para un acercamiento a algunos escolios alejandrinos en torno a pasajes homéricos referidos a la intervención divina o inadecuaciones narrativas, R. Nünlist, The Ancient Crtitic at Work. Terms and Concepts of Literacy Criticism in Greek Scholia, Cambridge, 2009, pp. 267-281.

7 Entre ellos Aristarco rechazaba la interpretación alegórica como un significado original del texto homérico y la ubicaba más bien como un significado añadido de los comentadores posteriores (F. Schironi, The Best of the Grammarians, University of Michigan Press, 2018, p. 140).

8 La primera evidencia textual se encuentra en Cicerón, Att. 2.20.3.2-3: «itaque posthac, si erunt mihi plura ad te

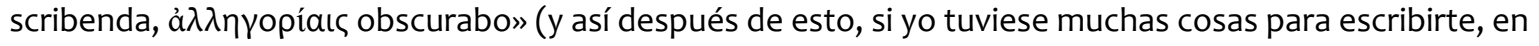
alegorías las ocultaría).

9 «Significado subyacente», Liddell H. G.; Scott R.; Jones H. S.; Mckenzie R. (9a ed. revisada), LSJ, A Greek English Lexicon, Oxford, Clarendon Press ( $1^{\mathrm{a}}$ ed. 1819), 1996, p. 1890; originalmente «sospecha», "conjetura» (P. Chantraine, Dictionnaire étymologique de la langue grecque. Histoire des mots, Paris: Klincksieck, 1968, p. 756). Se ha señalado que sería apropiado distinguir entre una «alegoría composicional», es decir, la actividad del autor/compositor que inserta una alegoría en su poema y, por otro lado, una «interpretación alegórica», lo que implicaría la actividad del lector/auditorio que interpreta el pasaje de la composición poética de modo alegórico (D. Califf, "Metrodorus of Lampsacus and the problem of allegory: an extreme case?", Arethusa 36, 2003, p. 25). Si bien esta distinción permitiría discernir entre las intenciones originales del compositor y las, eventualmente, interpretaciones «artificiales» o «forzadas» del texto, hay que tener en cuenta que, en primer lugar, se trata de una diferenciación moderna y que, incluso aplicada, los intentos de determinar uno y otro caso conducen a problemas aún mayores como, por ejemplo, los criterios para tal clasificación, sobre todo a razón de los escasos testimonios antiguos de los alegoristas en general y la falta de una crítica al respecto por parte de autores del periodo.

11 Para los filósofos presocráticos se utiliza la edición y nomenclatura de H. Diels, y W. Kranz (eds.), Fragmenta, Die Fragmente der Vorsokratiker 1-3, 6th edn. Berlin: Weidmann, 1903-1952.

12 Un escolio al Ars Grammatica de Dionisio Tracio afirma: «Pues la gramática más joven fue realizada a partir de

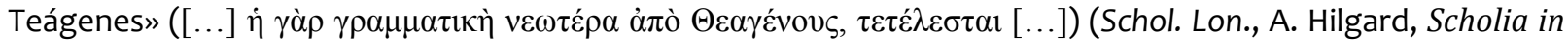
Dionysii Thracis. Artem Grammaticam, Olms, 1965, p. 448). Cfr. J. Svenbro, La parole et le marbr. Aux les origines de la poétique grecque, Lund, 1976, p. 111, para quien las tentativas de Teágenes de establecer una 
edición crítica de Homero revela una situación histórica en la que tiene lugar una transformación de la cultura oral y gentilicia en cultural escrita y política. Para una discusión más amplia sobre la tradición alegorista, sus orígenes e historia, R. Hunter The Measure of Homer. The Ancient Reception of the Iliad and the Odyssey, Cambridge, 2018, pp. 42-49, R. Nünlist, op. cit., pp. 267-281, A. Ford, The Origins of Criticism, Princeton, NJ, 2002, pp. 67-89, Feeney, op. cit., 1991, pp. 33-56, F. Buffière (ed.), Héraclite. Allégories d'Homère. Paris: Les Belles Lettres, 1962, pp. 9-34.

13 Cfr. J. Palmer, "The World of Early Greek Philosophy", en Sheffield, F., Warren, J., (eds.), The Routledge Companion to Ancient Philosophy, Routledge, 2014, pp. 56-60.

14 Véase n. 12. También Taciano, Oratio ad Graecos 31.2.2-7.

15 La alusión más temprana que tenemos sobre la alegorización de las theomachíai se remonta a Platón (Rep. 378d3-7): «En cuanto a los encadenamientos de Hera por su hijo y a los revoleos de Hefesto por su padre viniendo a defender a su madre golpeada, y en cuanto a las teomaquías, cuantas Homero ha compuesto, no debe ser aceptado para la ciudad, ni compuestas con alegorías ni sin alegorías» ("H

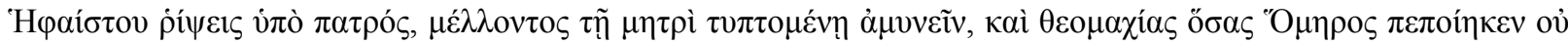

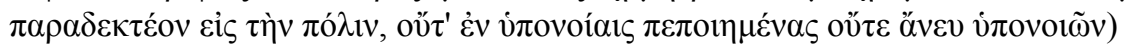

16 Para la traducción, cfr. A. Abritta et al., Ilíada: Canto 1. Traducción comentada. Segunda edición, ampliada y corregida, Buenos Aires: http://www.iliada.com.ar, 2020.

17 Si bien es evidente la diferencia entre $\Lambda \eta \tau \omega ́$ (madre de Apolo) y $\lambda \eta \dot{\eta} \theta \eta$ («olvido»), tanto $\tau$ como $\theta$ son dentales, con lo que la analogía etimológica propuesta por el alegorista resulta verosímil (además de compartir $\lambda \eta$-, por supuesto).

18 Cfr. Porf., Quaest. Hom. II. 20.67.1-16: «También, pues, dicen que lo seco combate con lo mojado, lo caliente con lo frío y lo liviano con lo pesado. Y aún el agua es la sofocadora del fuego y el fuego el secador del agua; y de igual modo con todos los elementos.[... ] apelando el fuego a Apolo y también a Helios y Hefesto, y el agua a Poseidón y al Escamandro y, de nuevo, la luna a rtemis, el aire a Hera y así al resto [... ] a Atenea con la prudencia, a Ares con la imprudencia, a Afrodita con el deseo, a Hermes con el discurso y a Leto con el olvido,

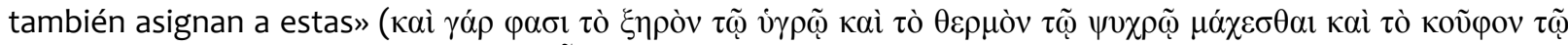

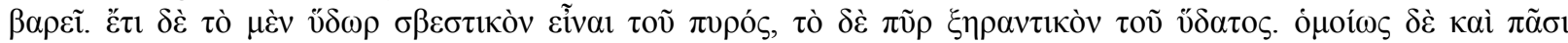

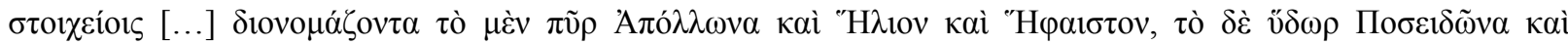

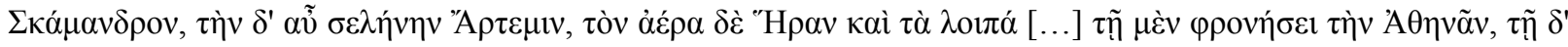

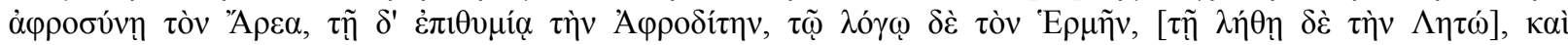
$\pi \rho о \sigma o 1 \kappa \varepsilon เ o \tilde{\sigma ı ~ \tau o v ́ \tau o เ \varsigma) ~ T a m b i e ́ n ~ P l a t o ́ n ~(C r a . ~ 404 c 2-3): ~ « Y ~ d e ~ i g u a l ~ m o d o ~ e l ~ l e g i s l a d o r, ~ e x a m i n a n d o ~ s o b r e ~ l o s ~}$

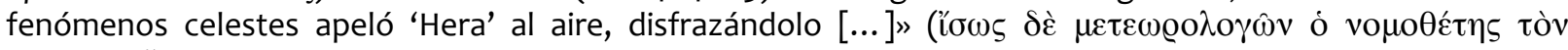

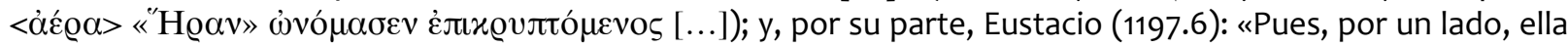

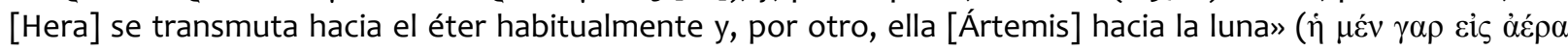

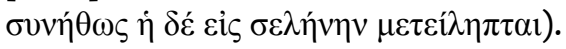

19 Algo que también puede advertirse en el lon de Platón cuando su personaje homónimo, haciendo referencia a algunos llamados por los críticos modernos «alegoristas homéricos», sostiene que ninguno de ellos supo decir

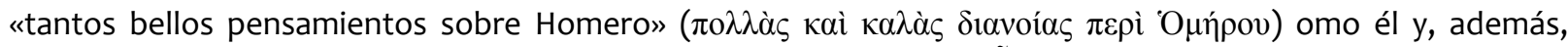

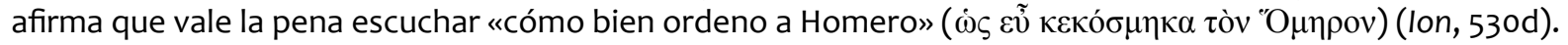

20 El enfoque racionalista propuesto por M. Domaradzki, "Theagenes of Rhegium and the rise of the allegorical interpretation", Elenchos 32 (2011), 205-227, para la interpretación alegórica en general y de Teágenes en particular, entendida como una etapa transicional en el pasaje del mito al lógos -más allá de en cierta medida intentar articular el quiebre conceptual un tanto forzado y artificial que perspectivas teóricas de décadas anteriores proponían-, vuelve a instalar una dicotomía mito-lógos, ya perimida hace tiempo.

21 Algunos de los problemas son la escasez de testimonios que aludan directamente a un tratamiento alegórico de la épica por parte de Ferécides y el hecho de que en la mayoría de los casos dichos testimonios constituyen referencias indirectas $y$, sobre todo, tardías, pudiendo haber sido contaminadas por la tradición alegorista a lo largo de varios siglos. Cfr. R. Pfeiffer, History of Classical Scholarship: From the Beginnings to the End of the Hellenistic Age, Oxford: University Press, 1968, p. 10; H. S. Schibli, Pherekydes of Syros, Oxford: University Press, 1990, cap. 4, n. 54.

22 Cfr. Schibli (op.cit. cap. 4, n. 54), para quien la cita de Ferécides no hace referencia a Il. 15.18-33, sino más bien a Il. 8.13-ss. en su alusión al Tártaro.

23 Está discutido si la tríada de divinidades primordiales eternas en Ferécides está constituida por Zeus, Chthonia y Cronos o bien por Zas, Chronos y Chthonia (7 B 1 DK). Tales fluctuaciones nominales -que no solo se relegan a 
Zeus/Zas- pueden deberse tanto a la metamorfosis/identificación divina operada en la misma obra de Ferécides, como a problemas textuales de la tradición manuscrita. Para una discusión sobre este problema, Schibli, op. cit., 1990, pp. 135-139.

Cfr. Platón, Cra. 391d-ss.

Los tres dominios, cielo, tierra y mar se establecen en el centro del escudo presentando una cosmogonía en la que se da el espacio como el lugar para la existencia del ser y el movimiento de los astros que figuran el tiempo y con ello el devenir del mundo humano (R. Thibau, "Le bouclier d'Achille", en F. Decreus (ed.), Hommages à Jozef Veremans. Collection Latomus193, Bruxelles, Latomus, 1986, 299-307).

Cfr. Anax. (12 A 10.9 DK) de quien se dice afirmaba que «una esfera de fuego surge en el aire que circunda la

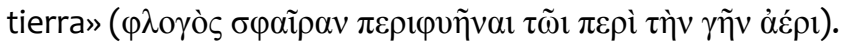

También en el testimonio de Ferécides (7 A 9 DK) citado anteriormente.

B. Cassin ("Sobre algunas escenas filosóficas primitivas en Homero", en N. Cordero (ed.), El filósofo griego frente a la sociedad de su tiempo, Buenos Aires: Rhesis, 2013, pp. 54-65) analiza tres pasajes homéricos advirtiendo cierta prefiguración de conceptualizaciones filosóficas para los autores del periodo posterior: $a$ ) la noción de ente expuesta por Parménides en su poema (Fr. 8) representado por Odiseo a partir de Od. 12.158-196, $b$ ) el concepto de phármakon abordado por Platón y Gorgias, entre otros, a partir de Od. 4.219-226, y c) el discurso performativo elaborado por la filosofía y la retórica del periodo Clásico, a partir de Od. 6.127-136. En el caso (a), el ente parmenídeo descripto en el fragmento 8.26-30, que se encuentra «દ̉v $\pi \varepsilon i ́ p a \sigma \iota ~ \delta \varepsilon \sigma \mu \omega \tilde{v} v$ (atándose a los

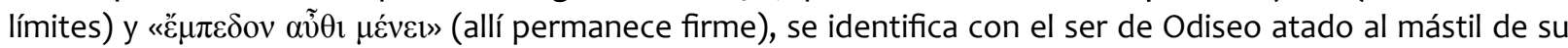

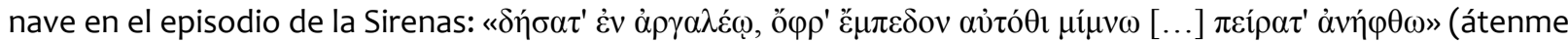
en lo penoso, para que allí firme yo permanezca [...] y ate los nudos/límites) (Od. 12.161-162). De modo que Cassin propone la identificación del ente parmenídeo con el héroe homérico a partir del cual el filósofo de Elea construye su análisis metafísico. En el caso (b), el episodio homérico en donde Helena prepara un brebaje, un

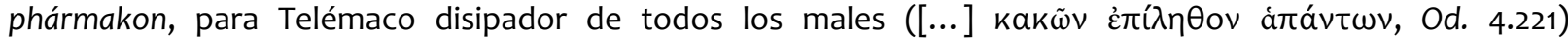

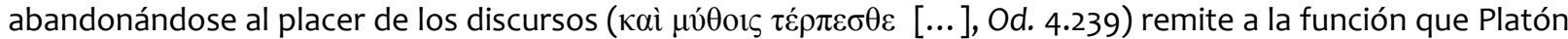
le otorga al discurso entendido como un phármakon, un remedio para el alma. Sobre esto último, cfr. Fhedr.

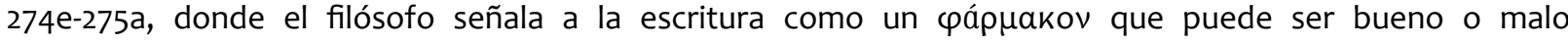
dependiendo de cómo se use. A su vez, en Teet. 167a se presenta al $\lambda$ ó platónicos: Chrm. 155e; Cra. 394a; Prt. 354a; Fhd. 63d; R., 459c; Ti. 89c; La. 649 a.

G. S. Kirk, J. E. Raven y M. Schofield, Los filósofos presocráticos. Historia crítica con selección de textos, Madrid, Gredos, 1983 [1957]; F. Buffière, Les Mythes d'Homère et la pensèe grecque, Paris, Les Belles Lettres, 1956; C. J. Emlyn-Jones, The Ionians and Hellenism: A Study of the Cultural Achievement of Early Greek Inhabitants of Asia Minor, London, Routledge, 1980; L. Versényi, Man's Measure: A Study of the Greek Image of Man from Homer to Sophocles, Albany, State University of New York Press, 1974.

o Es discutida la correspondencia exacta entre los elementos y las divinidades en la filosofía de Empédocles. Sobre este tema, P. Curd, "On the Question of Religion and Natural Philosophy in Empedocles", Perris (2005), pp. 137-162, O. Primavesi, "Empedocles: Physical and Mythical Divinity", en The Oxford Handbook of Presocratic Philosophy, P. Curd y D. W. Graham (eds.), Oxford: Oxford University Press, 2009, pp. 250-283.

31 Sobre todo a partir de los trabajos de Aristófanes, Zenódoto, Aristarco, entre otros, en donde hay una clara y deliberada función apologética de la alegórisis homérica, viendo a Homero como un poeta cuasidivino y sin errores, cuya máxima expresión se materializa en las atetizaciones.

Véase n. 19.

Ahora bien, no es necesario acordar con A. Ford, The Origins of Criticism, Princeton, NJ, 2002, en que esto implica una interpretación esotérica de los poemas homéricos por parte de los alegoristas del siglo VI a.C. en el modo que parece vislumbrarse en la interpretación enigmática de la cosmogonía Órfica del Papiro de Derveni (K. Tsantsanoglou "The First Columns of the Derveni Papyrus" and their Religious Significance" en Lacks, A. y Most, G. W. (eds.), Studies on the Derveni Papyrus, 1997, pp. 93-128; A. Bernabé Pajares, "The Derveni Papyrus: Problems of Edition, Problems of Interpretation," en Gagos, T. (ed.), Proceedings of the 25th International Congress of Papyrology, 2007, Ann Arbor, 2010, 77-83; A. Bernabé Pajares, "La Teogonía Órfica del Papiro de Derveni”, Arys 1999, 301-338). Pues, si se considera, por ejemplo, el lenguaje oracular de Heráclito y su exclusión de las masas en torno a la falta de entendimiento -por oposición a aquellos iluminados o inspirados divinamente que logran captar la verdad- ello no debe corresponderse, en este caso particular, a un secretismo de culto sino, en todo caso, a un tópico común entre los filósofos del periodo que puede encontrarse en varios de ellos 
(Heráclito, Parménides, etc.). El Papiro de Derveni es corrientemente analizado como un comentario alegórico de una teogonía órfica del siglo IV a.C. Para R. Janko, "The Derveni Papyrus. A New Translation", CP, 96, 2001, p. 2, el contenido del papiro se corresponde con un tratado en torno a la articulación entre los cultos populares, el lenguaje mistérico y la especulación filosóficas sobre la naturaleza de sesgo presocrático. En el mismo sentido M. L. West, The Orphic Poems, Oxford, 1983, p. 79, sostiene que el autor habría utilizado el texto, con sus referencias homéricas y órficas, para exponer sus propias doctrinas filosóficas. Para un tratamiento más exhaustivo de la cuestión, D. Torres, La escatología en la lírica de Píndaro y sus fuentes, Universidad de Buenos Aires, 2007, pp. 213-266. Por su parte H. S. Schibli, op. cit., 1990, pp. 68-69, establece algunos puntos en común entre la interpretación alegórica de Ferécides y el autor del Papiro de Derveni.

34 Cfr. Od.1.351-52, 8.496-98, para la aprobación del auditorio; Od.1.336-42, 8.536-41, para su reprobación. También puede advertirse en HHA III, 165-173.

35 A partir de ello puede traerse a colación a Cleantes que, con su Himno a Zeus, en el marco del estoicismo helenístico, logra transmitir sus enseñanzas filosóficas mediante una obra himnódica que adapta el detalle mitológico del dios supremo blandiendo el rayo para expresar, puede decirse, «alegóricamente», la doctrina estoica del fuego creador universal y todo ello dentro de un marco ritual prescripto por la religiosidad de dicha escuela. En este caso no se satisface la demanda de secularización racionalista que la crítica corrientemente ha propuesto como criterio filosófico, al contrario, hay una recurrencia al mito divino (aunque reformulado) que es expresado en un lenguaje épico-poético enmarcado en el género himnódico. Nada de ello impide el carácter preponderantemente filosófico su Himno a Zeus. Este ejemplo, aunque tardío, muestra la posibilidad de una composición alegórica intencionada por parte del poeta para expresar verdades filosóficas que están por debajo del sentido literal del poema, en alguna medida semejante, salvando las distancias, a lo que los alegoristas arcaicos pudieron haber advertido en los poemas homéricos. Sobre la alegórisis del estoicismo helenístico, M. H. Alesso, Interpretación alegórica de los textos homéricos en el siglo I: Heráclito el rhetor. Alegorías de Homero, Universidad Nacional de La Plata, Facultad de Humanidades y Ciencias de la Educación, 2001, pp. 54-72. 